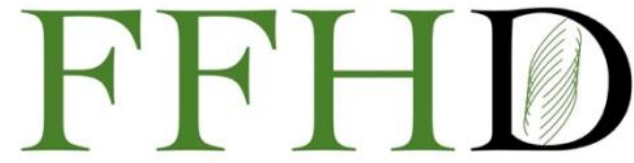

Functional Foods in Health and Disease

\title{
Effects of kefir consumption on carbohydrate profile of mother's milk
}

\author{
Tugce Tok Kurt, Caglar Gokırmaklı, Zeynep B. Guzel-Seydim*
}

Suleyman Demirel University, Department of Food Engineering, Isparta, Turkey

${ }^{*}$ Corresponding Author: Zeynep B. Guzel-Seydim, PhD, Suleyman Demirel University, Department of Food Engineering Isparta, Turkey

Submission Date: June 18 ${ }^{\text {th }}$, 2021; Acceptance Date: September $7^{\text {th }}, 2021$; Publication Date: September $14^{\text {th }}, 2021$

Please cite this as: Kurt T.T., Gokırmaklı C., Guzel-Seydim Z.B. Effects of kefir consumption on carbohydrate profile of mother's milk. Functional Foods in Health and Disease 2021. 11(9): 473-483. DOI: https://www.doi.org/10.31989/ffhd.v11i9.819
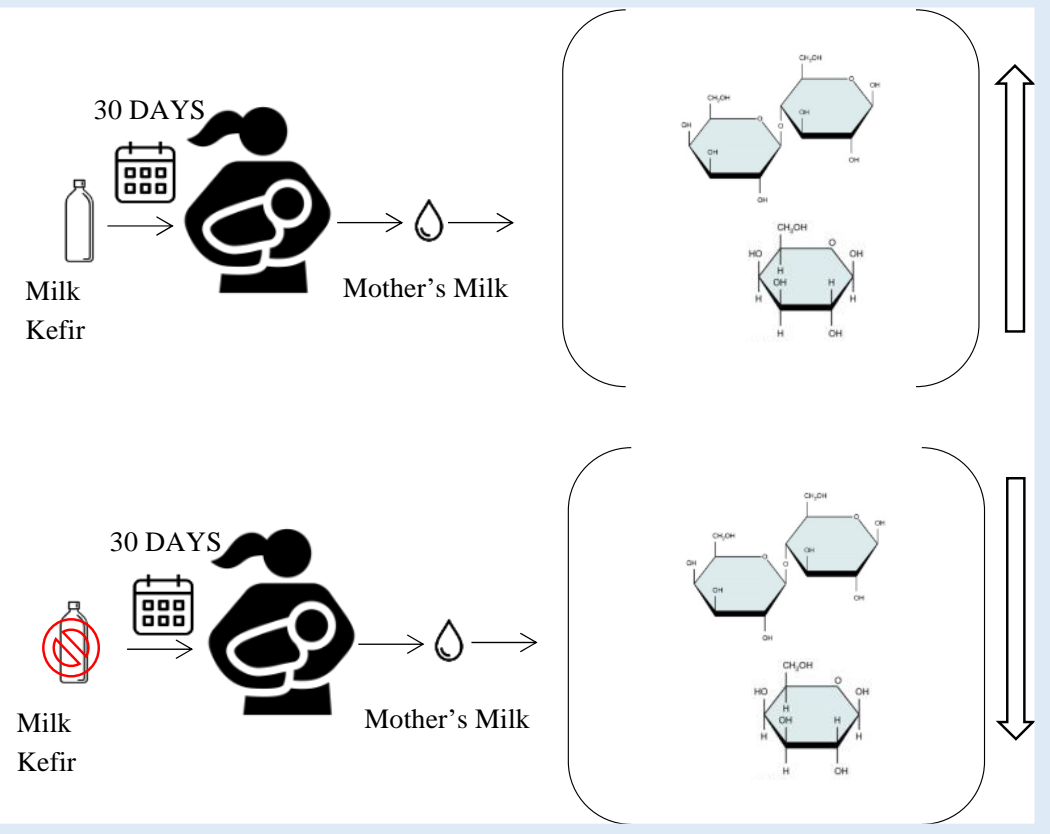

probiotic and prebiotic properties. Its abundant in terms of bioactive compounds, organic acids, volatiles as well as carbohydrates such as galactooligosaccharides which are important indigestible prebiotics. They help multiply the growth of beneficial microorganisms selectively and inhibit the growth of the pathogenic organism. In this aspect, it was hypothesized that consumption of traditional milk kefir may have positive effect on nutritional profile of mother's milk. However, there is no report on how milk kefir consumption may have effects on
\end{abstract}


composition of mother's milk. In this aspect, this study aimed to determine the effects of kefir consumption on the carbohydrate profiles of the mother's milk.

Methods: This study started immediately after birth, mothers were fed with $500 \mathrm{ml} /$ day of milk kefir made from kefir grains for 30 days in the KF group. Mothers who are in the control group (KI) continued their regular diet. Mother's milk samples were milked and collected during the day cycle into sterilized tubes and stored at $4^{\circ} \mathrm{C}$ until the analyses. Carbohydrate profile including GOS was determined using the liquid chromatographic method with the HI-PLEX column. Statistical analysis of the results was done by IBM SPSS v. 23.0 (Statistical Packages for Social Sciences) computer program. Data were grouped by mothers and type of consumption. In the analysis of differences between groups, One-Way ANOVA test was applied in parametric conditions and $p<0.05$ was considered as significant.

Results: The mean lactose concentrations of mother's milk who consumed kefir were 4,$68 ; 4,72 ; 5,89 \mathrm{~g} / 100 \mathrm{ml}$ on days 10 th, 20 th, and $30^{\text {th }}$, respectively. Glucose concentrations were 0,$29 ; 0,08 ; 0,21 \mathrm{~g} / 100 \mathrm{ml}$ on 10 th, 20 th, $30^{\text {th }}$ days, respectively. For the mother's milk samples in the control group, the averages of lactose concentration were 5,$42 ; 5,73 ; 5,51 \mathrm{~g} / 100 \mathrm{ml}$ on days 10 th, 20 th, and 30 th. Mothers who regularly consumed milk kefir had a tendency to contain more carbohydrate in their milk rather than control group. GOS peaks were also included depending on the rich content of prebiotics.

Conclusion: Consumption of authentic kefir may affect have effect on carbohydrate profile, including GOS of mother's milk.

Keywords: Human milk, kefir, prebiotic, galactooligosaccharides

CFFC 2021. This is an Open Access article distributed under the terms of the Creative Commons Attribution 4.0 License (http://creativecommons.org/licenses/by/4.0)

\section{INTRODUCTION}

Mother's milk is the best food with essential nutrients for babies, especially in their first year. It includes main nutritional components such as proteins, lipids, carbohydrates, minerals, vitamins, and bioactive factors. Nutrient factors and bioactive structures have vital beneficial impacts on newborns' development and immune system, e.g., long-time breastfeeding related to reduced overweight and obesity [1-3]. Among these nutrient factors, oligosaccharides (OS) exhibited about $20 \%$ of whole mother's milk carbohydrates. Until now, 150 different OS have been discovered in mother's milk. OS has essential functions for newborns, such as prebiotic, microbiota modulation, anti-pathogenic and immunomodulatory effects, possible impact on improving neurodevelopment, and intestinal barrier functions [1,4-5].

OS are carbohydrates consisting of 3-10 monosaccharide units, and they are the third principal component of mother's milk after lactose and lipids. Besides, OS indicates substantial physicochemical and physiological properties since they are prebiotic. Rich nutrition in the aspect of OS improves intestinal microecology. They produce energy by being fermented in the intestine by endogenous bacteria, acts as a metabolic substrate, convert into short-chain fatty acids [6]. These compounds contribute to the development of probiotics [7]. In colostrum, OS reaches its maximum concentration (above $20 \mathrm{~g} / \mathrm{L}$ ), and after a few weeks, it is $12-14 \mathrm{~g} / \mathrm{L}$ in milk 
[8-9]. Galactooligosaccharides (GOS) is one of the most produced oligosaccharides in the world. It is found naturally in breast milk but, it is also synthesized artificially [10]. GOS is formed by the binding of galactose molecules to lactose. Structurally, it is formed due to binding 3 to 6 saccharides and 2 to 5 galactose via mostly $(1-4 ; 1-6)$ bonds [11]. Studies on the metabolism of oligosaccharides in human milk have indicated that these substances are resistant to digestion [12-13] and stimulate the dominant flora rich in probiotics [14].

In nature, two types of kefir are present, e.g. milk kefir and water kefir [15]. In the context of this study, milk kefir was used. Milk kefir is known for its health-friendly properties such as hepatoprotective effect, gastroprotective effect, anti-microbial, anti-inflammatory, anti-oxidant, anti-allergic, anti-fatique, anti-carcinogenic and anti-viral effects [15-16]. One of the more recent studies [17] investigated how carbohydrate profile of kefir altered during the fermantation process. It concluded that the GOS content of milk kefir was altered by fermantation process. The present study aimed to determine the effects of kefir consumption on the carbohydrate profiles of the mother's milk.

\section{MATERIALS AND METHODS}

2.1. Standards and Chemicals: The standards used in the study, lactose, glucose, galactose, and lactic acid were obtained from Sigma Aldrich (Saint Louise, USA). Hexane and sodium hydroxide were obtained from Sigma Aldrich (Saint Louise, USA). HI-PLEX Na (Octo) 300x7.7 mm column was utilized (Agilent Technology, Santa Clara, USA). As the mobile phase, $0.015 \mathrm{~N} \mathrm{NaOH}$ was prepared with ultrapure water and used. An industrial brand GOS mixture product; $\beta$-D-Gal (1 $\rightarrow 4)-D-($ Galactobiose) and $\beta$-D-Gal $(1 \rightarrow 6)-D$ (Galactobiose) from Sigma Aldrich (Saint Louise, USA) were used as standards.
2.2. Preparation of traditional milk kefir: Pasteurized milk and kefir grains were obtained from Danem Inc. (Technopark, Isparta, Turkey). Pasteurized milk was fermented with the grains $(2 \%)$ at $25^{\circ} \mathrm{C}$. Fermentation was terminated at $\mathrm{pH}$ 4.6. Milk kefir grains were sieved with a sterilized plastic sieve and obtained ready-to-drink milk kefir samples were stored at $4^{\circ} \mathrm{C}$.

2.3. Study design: In this study, the breast milk samples were collected from eleven healthy mothers in Isparta (Turkey) were tested. Ethics committee approval was obtained from Süleyman Demirel University Medical Faculty Clinical Research Ethics Committee (2012-KAEK-38). In addition, the necessary information was given to the mothers, and the prepared protocol was signed.

As the research plan in this study, 11 mothers who had just given birth were separated into two groups. In the first group, 8 of 11 mothers consumed $500 \mathrm{~mL} /$ day traditional milk kefir, coded as KF. The amount of kefir was adjusted based on other studies [18-20], which changed between 400-600 mL/day. In the second group, the control group, 3 of 11 mothers continued their regular diets without consuming kefir, coded as KI. Mothers were selected based on their health status and volunteering basis. The study was completed with all participated mothers without any exclusion. To reduce microbiological content from environmental contamination, mothers first cleaned breasts with soap and sterilized water. During the study, the 10th day (colostrum), 20th day (mature milk), and 30th-day mother's milk samples were collected directly into sterilized tubes during the day cycle and stored at $4^{\circ} \mathrm{C}$ until the analysis. It was considered that 10-day intervals would be sufficient to observe if any differences occurred.

2.4. Preparation of mother's milk sample: Firstly, mother's milk was centrifuged at 15,000 rpm for $10 \mathrm{~min}$, and some parts of fat and proteins were suspended. Then, serum, e.g., the rest remaining from fats and proteins, was stored 1 day under $-20^{\circ} \mathrm{C}$. Then, the sample was transferred to another tube to remove the protein residues at the bottom and for this purpose, centrifuged at $15,000 \mathrm{rpm}$ for 5 minutes. The 
samples were filtered through a coarse filter to remove fat and protein residues once again. The samples were then passed through a 0.45-micron membrane, and finally treated with the oil solvent hexane to remove oil particles. The upper phase was removed and kept at $48^{\circ} \mathrm{C}$ for 30 minutes to remove the hexane residue.

2.5. Latic Acid Analysis: HI-PLEX Na (Octo) column was used to analyze the lactic acid content of the samples. As the mobile phase, $0.015 \mathrm{~N} \mathrm{NaOH}$ was utilized, and the flow rate was adjusted to $0.8 \mathrm{~mL} / \mathrm{min}$.
2.6. Carbohydrate Profile Analysis: The liquid chromatography (Shimadzu, Japan) was used to determine the carbohydrate composition. HI-PLEX Na (Octo) column with refractive index detector was utilized. The mobile phase was $0.015 \mathrm{~N} \mathrm{NaOH}$, and the flow rate was $0.8 \mathrm{~mL} / \mathrm{min}$. These optimized values were obtained as a result of preliminary trials. Lactose, glucose, and galactose standard curves were formed. Then, the lactose, glucose, galactose amounts, and GOS peaks of the samples were determined (Figure 1).

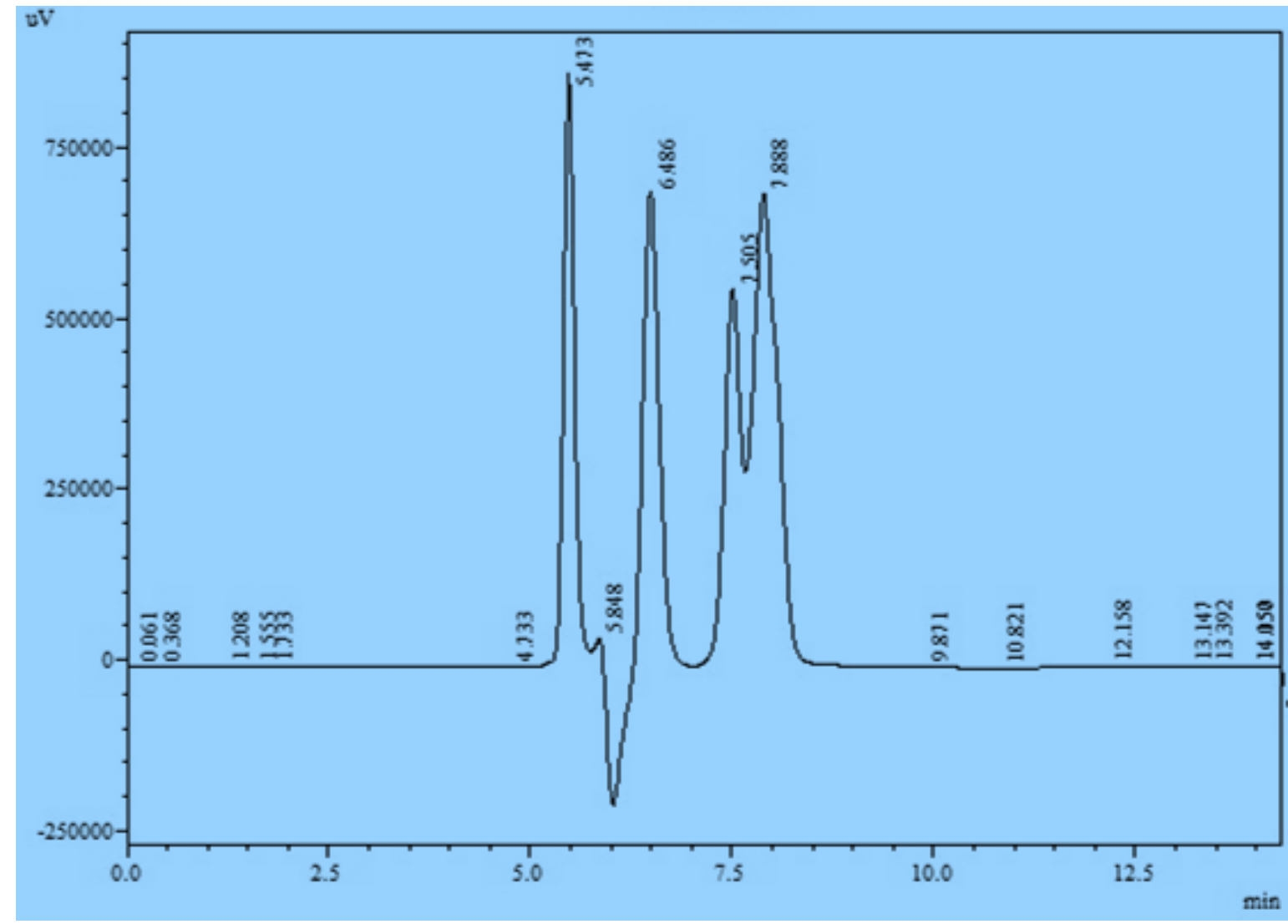

Figure 1. Retention times of lactic acid, lactose, glucose, galactose

In addition, in this study, the galactooligosaccharides contents of milk belonging to mothers were predicted based on standards. Retention times of $\beta-D-G a l(1 \rightarrow 4)-D$ Galactobiose and $\beta-D-G a l \quad(1 \rightarrow 6)-D$ Galactobiose standard peaks were determined as examples of galactooligosaccharides (Figure 2 and Figure 3). It appears that the retention times are reasonably close to lactose. The retention time of the commercial GOS mixture is also illustrated in Figure 4. 


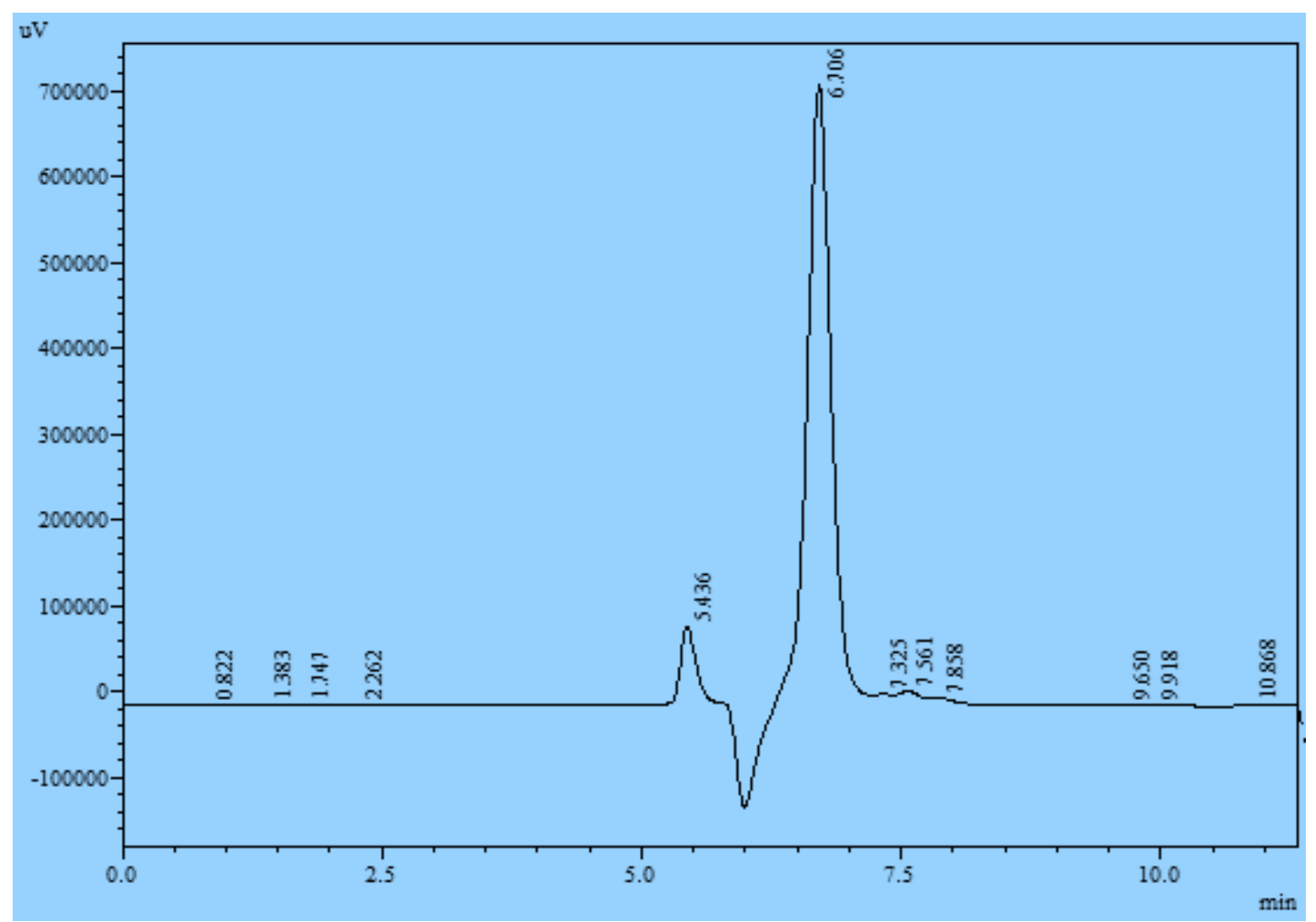

Figure 2. $\beta$-D-Gal (1 $\rightarrow 4)-D-G a l$ (Galactobiose) retention time

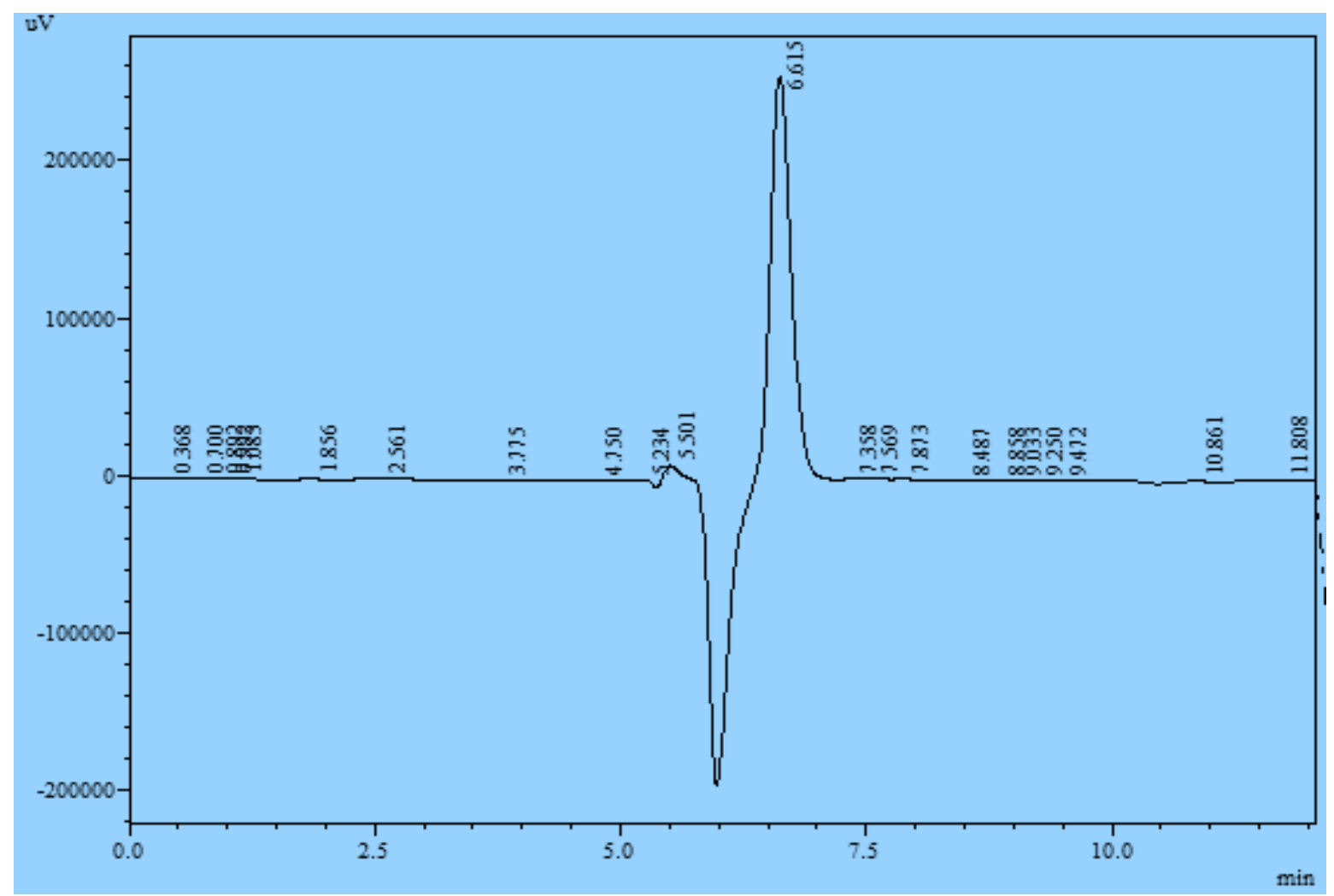

Figure 3. $\beta$-D-Gal (1 $\rightarrow 6)-D-G a l$ (Galactobiose) retention time 


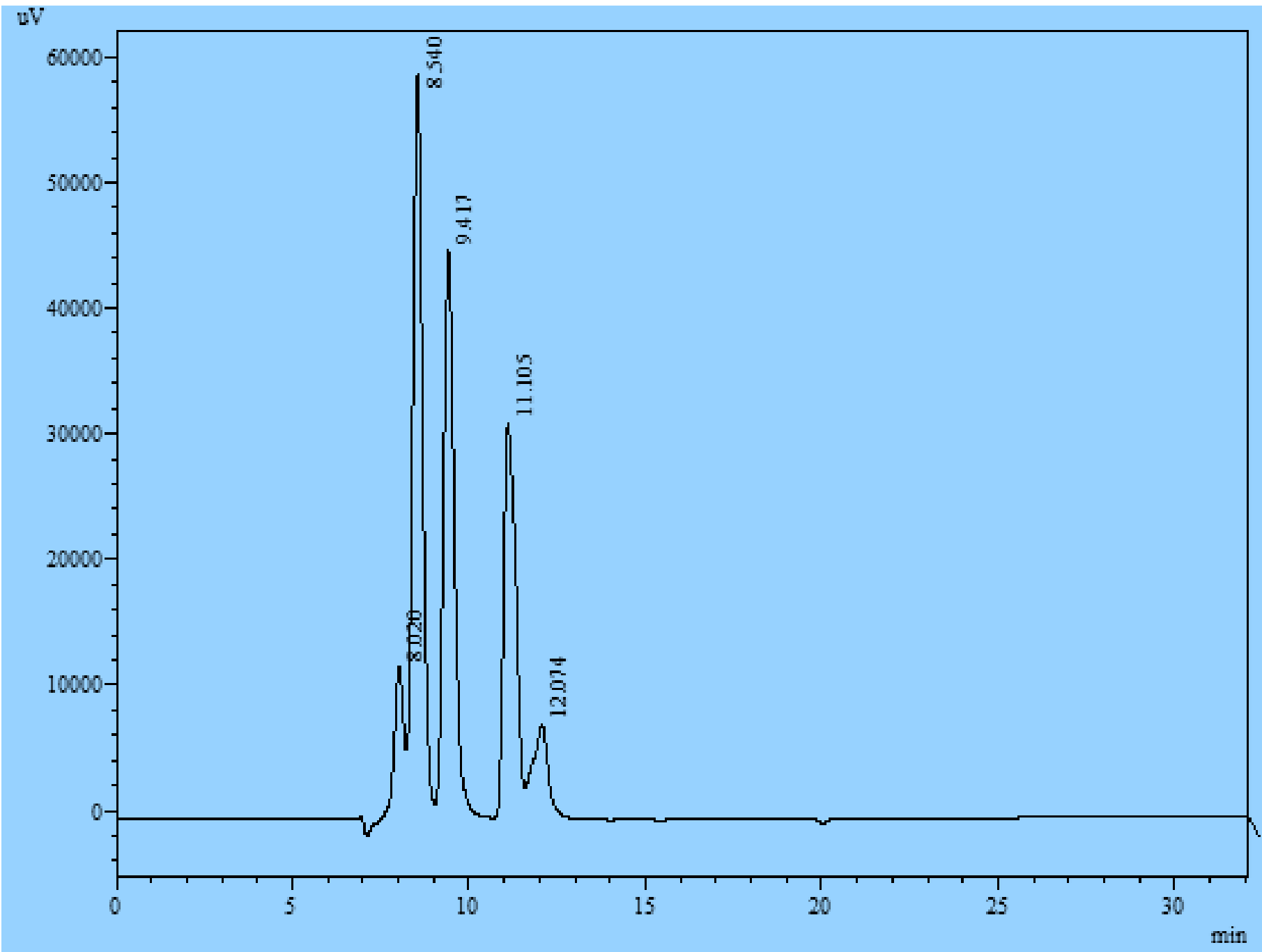

Figure 4. Retention times of commercial GOS

2.7. Statistical analysis: Statistical analysis of the results was done by IBM SPSS v. 23.0 (Statistical Packages for Social Sciences) computer program. Data were grouped by mothers and type of consumption. In the analysis of differences between groups, One-Way ANOVA test was applied in parametric conditions and $p<0.05$ was considered as significant.

\section{RESULTS AND DISCUSSION}

3.1. Lactic acid content: Lactic acid contents of milk belonging to the $\mathrm{KF}$ group were determined as 0,82 $\mathrm{g} / 100,0,68 \mathrm{~g} / 100 \mathrm{ml}$, and 1,63 g/100 $\mathrm{ml}$ for the 10th, 20th, and 30th days. On the other hand, lactic acid contents of milk belonging $\mathrm{KI}$ group were determined as $0,85 \mathrm{~g} / 100 \mathrm{ml}, 0,60 \mathrm{~g} / 100 \mathrm{ml}, 0,49 \mathrm{~g} / 100 \mathrm{ml}$ for the 10 th, 20th, and 30th days, respectively (Table 1 ). According to the results, the lactic acid content of the $\mathrm{KI}$ group decreased during the study. Moreover, milk of the KF group had a significantly higher lactic acid content than the milk of the KI group on the 30th day $(P<0,05)$ (Figure 5.). During the kefir fermantation, lactic acid content gradually inceases [17]. Higher content of lactic acid was detected the milks of KF group. 


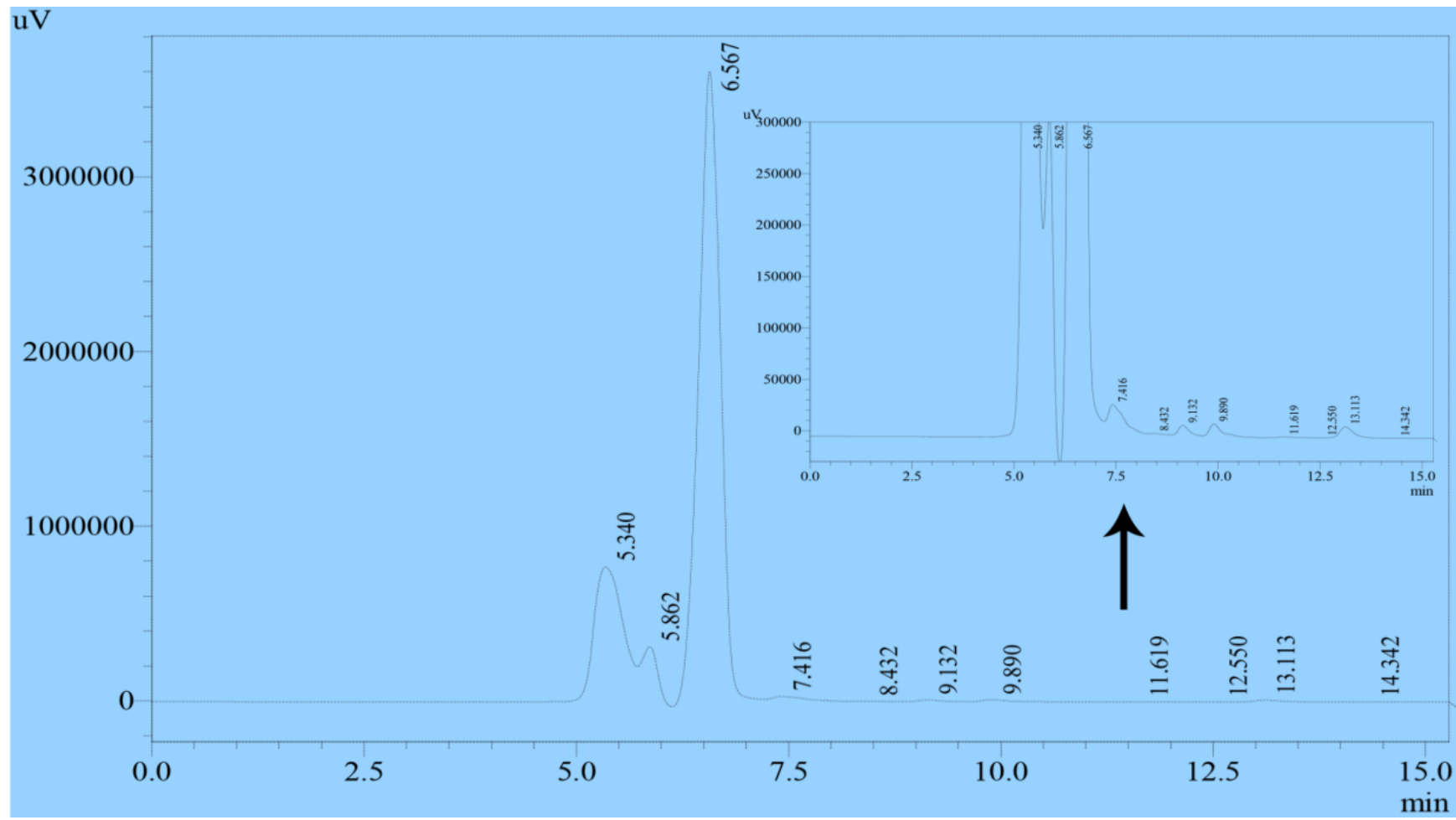

Figure 5. Chromatogram of KF group on $30^{\text {th }}$ day

3.2. Lactose content: The lactose content of milk belonging to the $\mathrm{KF}$ group was not significantly changed between the 10th and 20th day (Table 1). Because, according to the recent knowledge, diet does not have impact on lactose composition of mother's milk [21].
However, a significant increase was observed on the 30th day, and the value was determined as 5,89 $\pm 0,23 \mathrm{~g} / 100$ $\mathrm{mL}$ (Table 1). The nature of postpartum period may have resulted in significant increase [22]. According to statistical

Table 1. Carbohydrate profile and lactic acid content of samples

\begin{tabular}{ccccc}
\hline Groups & $\begin{array}{c}\text { Sample } \\
(\mathrm{g} / 100 \mathrm{~mL})\end{array}$ & Day 10 & Day 20 & Day 30 \\
\hline $\mathrm{KF}$ & Lactic acid & $0.82 \pm 0.27$ & $0.68 \pm 0.41$ & $1.63 \pm 0.45^{\mathrm{Aa}}$ \\
$\mathrm{KI}$ & Lactose & $0.85 \pm 0.08$ & $0.60 \pm 0.09$ & $0.49 \pm 0.01^{\mathrm{Ab}}$ \\
\hline $\mathrm{KF}$ & $4.68 \pm 0.39$ & $4.72 \pm 0.21$ & $5.89 \pm 0.23^{\mathrm{A}}$ \\
$\mathrm{KI}$ & $5.42 \pm 0.37^{\mathrm{a}}$ & $5.73 \pm 0.28^{\mathrm{a}}$ & $5.51 \pm 0.61$ \\
\hline $\mathrm{KF}$ & Glucose & $0.290 \pm 0.01^{\mathrm{a}}$ & $0.083 \pm 0.002^{\mathrm{A}}$ & $0.213 \pm 0.031^{\mathrm{a}}$ \\
$\mathrm{KI}$ & $0.107 \pm 0.001^{\mathrm{B}}$ & $0.161 \pm 0.257^{\mathrm{A}}$ & $0.125 \pm 0.0008^{\mathrm{B}}$ \\
\hline $\mathrm{KF}$ & \multirow{2}{*}{ Galactose } & $0.016 \pm 0.001$ & $*$ & $0.019 \pm 0.001$ \\
$\mathrm{KI}$ & & $*$ & $*$ & $0.0086 \pm 0.001^{\mathrm{Ab}}$ \\
\hline
\end{tabular}

Capital letters represent significance during the length of kefir consumption in the rows, and lower case letters indicate the significance between the different groups on the same day $(p<0.05)$.

*Below the Limit of Detection

Capital letters represent significance during the length of kefir consumption in the rows, and lower case letters indicate the significance between the different groups on the same day $(p<0.05)$. *Below the Limit of Detection 
analysis results, there were significant differences between the KF and KI groups on the 10th and 20th days $(P<0,05)$. It was reported that the lactose content of the mother's milk was $6.7 \mathrm{~g} / 100 \mathrm{~mL}$. Lactose is the most abundant solid component of thmother's milk. Its amount in mother's milk is higher than other species [323]. In other studies, lactose content of mother's milk was determined between as 5.97-6.28 g/100 mL [24] and 5.76-6.78 g/100 $\mathrm{mL}$ [25] during the different times of lactation period.

\subsection{Glucose content: Mothers (KI) who did not consume} kefir had lower glucose content in their milk than mothers who consumed kefir on the 10th and $30^{\text {th }}$ days $(P<0.05)$ (Table 1). According to our results, there was a significant difference in glucose content between KF and KI groups $(P<0.05)$ (Table 1$)$. The glucose content of various milk of mothers was reported as $0.025 \mathrm{~g} / 100 \mathrm{~mL}$ [26] and $0.032 \mathrm{~g} / 100 \mathrm{~mL}$ [27].

3.4. GOS content: GOS peaks for our samples and commercial GOS mixture were detected in similar time intervals. These were predicted as mother's milk oligosaccharides (Table 2). GOS content of samples was shown in Figures 6 and 7; however, quantification of GOS was not possible in this study. It was reported that mother's milk contains a significant amount of OS, as much as $1-10 \mathrm{~g} / \mathrm{L}$ in mature breast milk and $15-23 \mathrm{~g} / \mathrm{L}$ in colostrum [3].

Table 2. Retention times of galactooligosaccharides (min)

\begin{tabular}{|ccccc|}
\hline GOS 1 & GOS 2 & GOS 3 & GOS 5 \\
\hline $\mathbf{5 . 8}$ & 9.1 & 9.8 & 11.4 & 13.0 \\
\hline
\end{tabular}

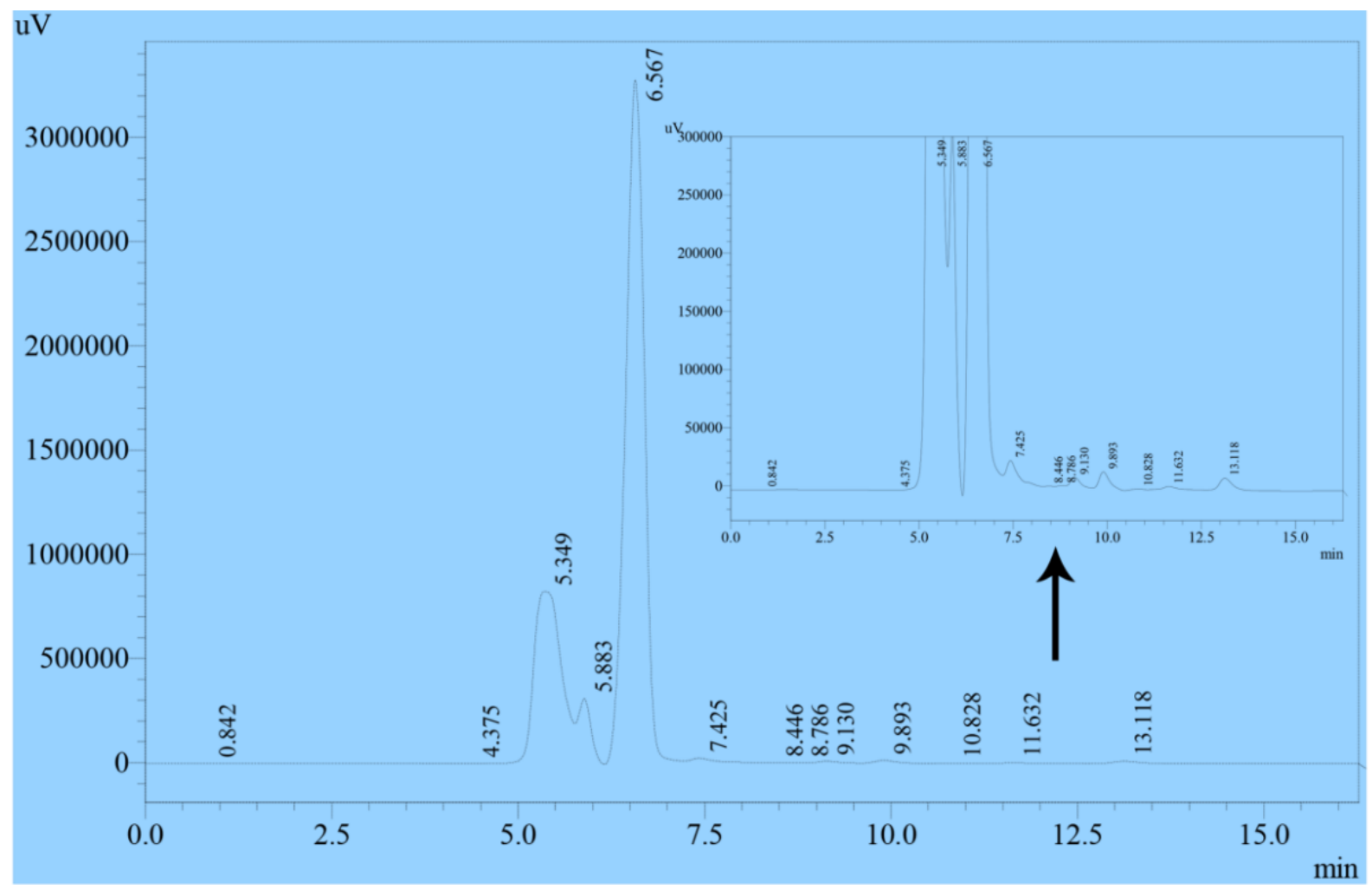

Figure 6. Possible GOS content of samples (kefir consumed mothers' milk) 


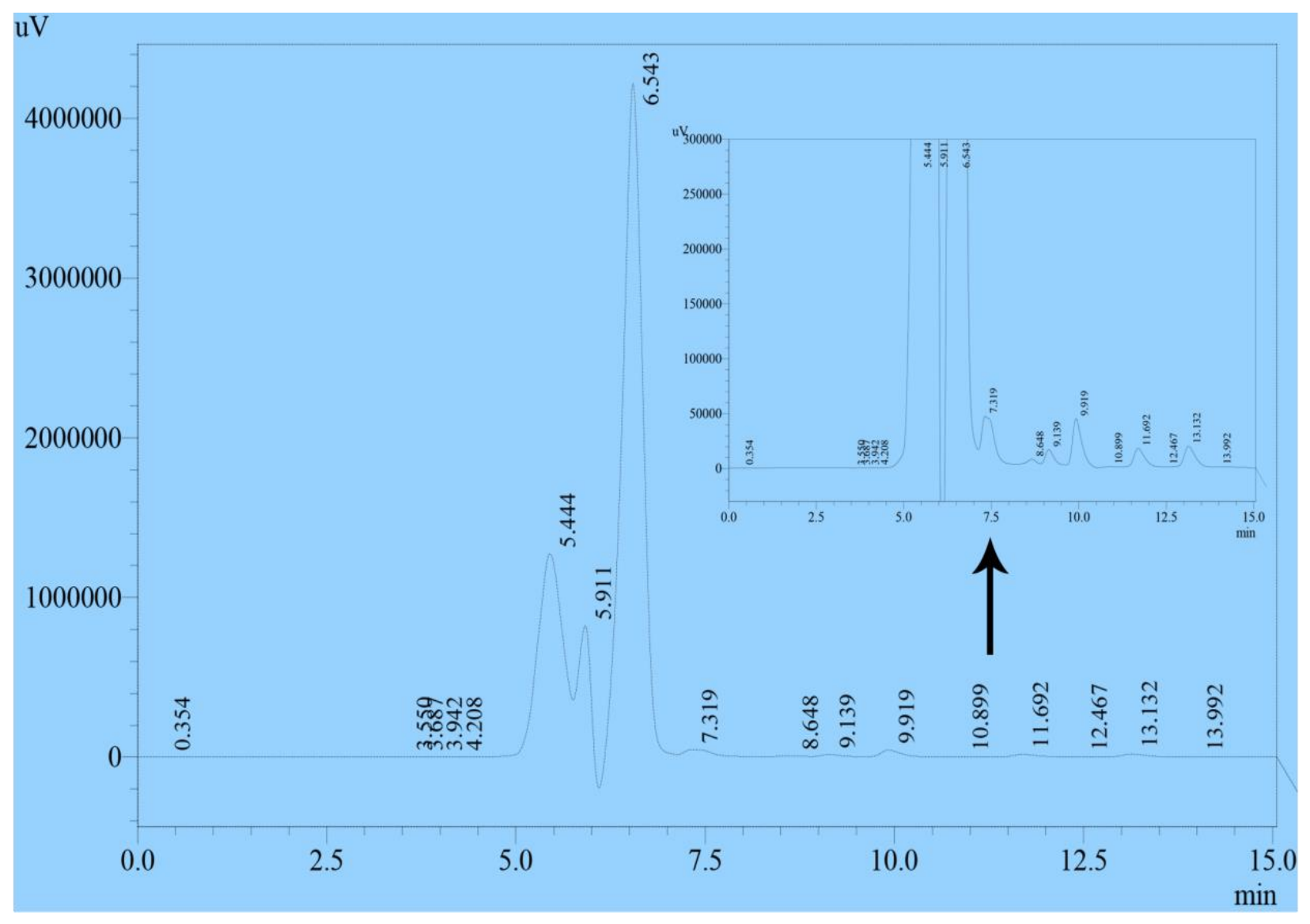

Figure 7. Possible GOS content of mother's (who did not consume kefir) milk

\section{CONCLUSION}

Mother's milk with a high content of oligosaccharides supports the prebiotic range originating from kefir. The lactose content of mother's milk increased after 30 days of regular kefir consumption. In this study, peaks predicted to be GOS were detected in the samples for both KF and KI. Consumption of authentic kefir (made from kefir grains) may affect the carbohydrate profile, including GOS of mother's milk. These structures with prebiotic properties may support the baby's intestinal microbiota. The feedback of mothers who consumed kefir was also positive; they stated that they did not experience any intestinal problems in themselves and their babies. They also said that they would continue to include kefir in their diet. This is the first study on the effect of kefir consumption on the carbohydrate profile of breast milk. Further studies are needed to detect the effects of healthy nutrition on mother's milk.
Abbreviations: OS: oligosaccharides, GOS: galactooligosaccharides, KF: mothers who consumed kefir during the study, KI: control group who did not consume kefir during the study

Authors' Contribution: Tugce Tok Kurt performed the analyses, Caglar Gokırmaklı helped writing and critically revising manuscript, Zeynep Banu Seydim designed the study, analyzed data, supervising and contributed fundamental conceptualization for the research and write and edit the manuscript.

Competing Interests: There are no conflicts of interest to declare.

Acknowledgment/Funding: This study has been financially supported by the Scientific Research Projects 
Unit of Suleyman Demirel University, Isparta, Turkey, Project Number: 5055-YL2-17. We thank Tugce Tunay for

\section{REFERENCES}

1. Cheng L, Akkerman R, Kong C, Walvoort MTC, de Vos P. More than sugar in the milk: Human milk oligosaccharides as essential bioactive molecules in breast milk and current insight in beneficial effects. Crit Rev Food Sci Nutr 2021;61(7):1184-1200.

2. Meng $\mathrm{F}$, Uniacke-Lowe $\mathrm{T}$, Ryan CA, Kelly AL: The composition and physico-chemical properties of human milk: A review. Trends Food Sci Technol 2021, 112:608-621

3. Mosca F, Giannì ML: Human milk: Composition and health benefits. Pediatr Med Chir 2017, 39(2):155.

4. Jorgensen JM, Young R, Ashorn P, Ashorn U, Chaima D, Davis JC, Dewey KG: Associations of human milk oligosaccharides and bioactive proteins with infant growth and development among Malawian mother-infant dyads. Am J Clin Nutr 2021, 113(1):209-220.

5. Thurl S, Munzert M, Boehm G, Matthews C, Stahl B: Systematic review of the concentrations of oligosaccharides in human milk. Nutr Rev 2017, 75(11):920-933.

6. Quigley EM: Prebiotics and probiotics: Modifying and mining the microbiota. Pharmacol Res 2010, 61(3):213-218.

7. Qiang $\mathrm{X}$, YongLie $\mathrm{C}$, QianBing W: Health benefit application of functional oligosaccharides. Carbohydr Polym 2009, 77(3):435441.

8. Coppa GV, Gabrielli O, Pierani P, Catassi C, Carlucci A, Giorgi PL: Changes in carbohydrates composition in human milk over 4 months of lactation. Pediatrica 1993, 91:637-641.

9. Coppa GV, Pierani P, Zampini L, Carloni I, Carlucci A, Gabrielli O: Oligosaccharides in human milk during different phases of lactation. Acta Paediatr 1999, 430:89-94.

10. Cho SS, Finocchiaro T: Handbook of prebiotics and probiotics ingredients: Health benefits and food applications. CRC Press: 2009.

11. Sako T, Matsumoto $K$, Tanaka R: Recent progress on research and applications of non-digestible galactooligosaccharides. Int Dairy J 1999, 9(1):69-80.

12. Engfer MB, Stahl B, Finke B, et al: Human milk oligosaccharides are resistant to enzymatic hydrolysis in the upper gastrointestinal tract. Am J Clin Nutr 2000, 71:1589-96.

13. Coppa GV, Pierani P, Zampini L, Bruni S, Carloni I, Gabrielli O: Characterization of oligosaccharides in milk and feces of breastfed infants by high-performance anion-exchange chromatography. Adv Exp Med Biol 2001, 501:307-14. providing mother milk samples from her thesis research projeect.

14. Coppa GV, Bruni S, Morelli L, Soldi S, Gabrielli O: The first prebiotics in humans: Human milk oligosaccharides. J Clin Gastroenterol 2004, 38:S80-583.

15. Guzel-Seydim ZB, Gökırmaklı Ç, Greene AK: A comparison of milk kefir and water kefir: Physical, chemical, microbiological and functional properties. Trends Food Sci. Technol 2021, 113:42-53.

16. Hamida RS, Shami A, Ali MA, Almohawes ZN, Mohammed AE, Bin-Meferij MM: Kefir: A protective dietary supplementation against viral infection. Biomed Pharmacother 2021, 133: 110974.

17. Hikmetoglu M, Sogut E, Sogut O, Gokirmakli C, Guzel-Seydim ZB: Changes in carbohydrate profile in kefir fermentation. Bioact Carbohydr Diet Fibre 2020, 23:100220.

18. Alihosseini N, Moahboob SA, Farrin N, Mobasseri M, Taghizadeh A, Ostadrahimi AR: Effect of probiotic fermented milk (kefir) on serum level of insulin and homocysteine in type 2 diabetes patients. Acta Endocrinol 2017, 13 (4):431-436.

19. Fathi Y, Ghodrati N, Zibaeenezhad MJ, Faghih S: Kefir drink causes a significant yet similar improvement in serum lipid profile, compared with low-fat milk, in a dairy-rich diet in overweight or obese premenopausal women: A randomized controlled trial. J Clin Lipidol 2017, 11(1):136-146.

20. Yılmaz I, Dolar ME, Ozpınar H: Effect of administering kefir on the changes in fecal microbiota and symptoms of inflammatory bowel disease: A randomized controlled trial. Turk J Gastroenterol 2019, 30:242-253.

21. Karcz K, Królak-Olejnik B: Vegan or vegetarian diet and breast milk composition-A systematic review. Crit Rev Food Sci Nutr 2021, 61(7):1081-1098.

22. Hsu YC, Chen CH, Lin MC, Tsai CR, Liang JT, Wang TM: Changes in preterm breast milk nutrient content in the first month. Pediatr Neonatol 2014, 55(6):449-454.

23. Plaza-Díaz J, Fontana L, Gil A: Human milk oligosaccharides and immune system development. Nutrients 2018, 10(8):1038.

24. Mitoulas LR, Kent JC, Cox DB, Owens RA, Sherriff JL, Hartmann $\mathrm{PE}$ : Variation in fat, lactose and protein in human milk over $24 \mathrm{~h}$ and throughout the first year of lactation. $\mathrm{Br} J$ Nutr 2002, 88(1):29-37.

25. Paul VK, Singh M, Srivastava LM, Arora NK, Deorari AK: Macronutrient and energy content of breast milk of mothers delivering prematurely. Indian J Pediatr 1997, 64(3):379-382. 
26. Goran $\mathrm{MI}$, Martin AA, Alderete TL, Fujiwara H, Fields DA: Fructose in breast milk is positively associated with infant body composition at 6 months of age. Nutrients 2017, 9(2):146.
27. Suman A, Mallory B, Sybil LH, Carmen RS, Julian ES, Barbara CP, Barbara GS: Glucose and insulin levels are increased in obese and overweight mothers' breast-milk. Food Nutr Sci 2011, 2(3):201-206 